\title{
Perbandingan Visualisasi Hasil Deteksi Area Terbangun Berdasarkan Metode Maximum Likelihood Classification (MLC) dan Normalized Difference Built-Up Index (NDBI)
}

\author{
Visualization Comparison of Built-Up Area Detection Based on Maximum Likelihood \\ Classification (MLC) and Normalized Difference Built-Up Index (NDBI) Methods
}

\author{
Alifah Noraini* ${ }^{*}$ Adkha Yulianandha Mabrur \\ Program Studi Teknik Geodesi, Fakultas Teknik Sipil dan Perencanaan, Institut Teknologi \\ Nasional Malang, Indonesia. \\ Corresponding Author: alifah.noraini@lecturer.itn.ac.id
}

\begin{abstract}
ABSTRAK
Salah satu faktor akibat dari aktivitas manusia terhadap perubahan lingkungan adalah perubahan tutupan lahan, terutama area terbangun. Dibutuhkan metode yang cepat dan akurat untuk monitoring perubahan area terbangun agar sesuai dengan perencanaan yang terdapat dalam Rencana Tata Ruang Wilayah (RTRW). Salah satu teknologi yang digunakan adalah teknologi penginderaan jauh. Data utama yang digunakan adalah citra satelit Landsat 8. Metode yang digunakan menggunakan metode Maximum Likelihood Classification (MLC) dan algoritma Normalized Difference Built-up Index (NDBI). Analisis yang dilakukan dalam penelitian ini adalah analisis secara visualisasi.
\end{abstract}

Kata kunci: Area bangunan, NDBI, MLC

\begin{abstract}
One factor that results from human activities on environmental change is changes in land cover, especially built-up area. A fast and accurate method for monitoring changes in built-up areas is needed to match the planning contained in document of Rencana Tata Ruang Wilayah (RTRW). One of technologies used is remote sensing technology. Main data used is Landsat 8 satellite imagery. The method used is the Maximum Likelihood Classification (MLC) method and the Normalized Difference Built-up Index (NDBI) algorithm. Analysis conducted in this study is a visualization analysis.
\end{abstract}

Keywords: Built-up area, NDBI, MLC

\section{PENDAHULUAN}

Lingkungan merupakan suatu hal yang bersifat dinamis. Salah satu faktor yang mempengaruhi perubahan lingkungan adalah aktivitas manusia. Salah satu akibatnya adalah perubahan tutupan lahan, terutama lahan terbangun. Pengelolaan perubahan lahan ini tidak hanya mempersiapkan dan mengadopsi dokumen perencanaan, pengelolaan tersebut juga membutuhkan implementasi untuk menjalankan kebijakan umum, pengawasan dampak perencanaan, dan membangun komunikasi secara terusmenerus dengan masyarakat dan kepentingan kelompok. Dibutuhkan teknik yang cepat dan akurat untuk monitoring lingkungan agar tidak terjadi perubahan lahan yang tidak sesuai dengan dokumen Rencana Tata Ruang Wilayah (RTRW).
Salah satu analisa yang dapat digunakan untuk memonitoring lahan adalah analisa pemetaan wilayah tersebut. Menurut Khamala dan Ottichilo (2002), analisa teknik pemetaan konvensional menggunakan foto udara hitam putih dan lapangan di Afrika adalah lambat, rumit, serta mahal sehingga jika terus menerus dilakukan dirasa kurang terjangkau bagi negara tersebut. Solusinya adalah menggunakan citra satelit dalam proses updating-nya. Citra penginderaan jauh secara ideal digunakan untuk memantau dan mendeteksi tanah mencakup perubahan yang sering terjadi di daerah perkotaan dan pinggiran kota sebagai akibat urbanisasi yang terus-menerus (Zha.dkk, 2003).

Area terbangun merupakan perubahan lahan yang paling pesat setiap tahun. Area terbangun yang tidak sesuai penggunaannya dalam dokumen perancanaan dapat 
diminimalisir dengan melakukan monitoring secara berkala. Metode ekstraksi yang digunakan berdasarkan citra satelit, terdiri dari 2 (dua) macam, yaitu klasifikasi nilai Digital number (DN) berbasis piksel dan berbasis objek. Dalam penelitian ini bertujuan membandingkan metode untuk ekstraksi bangunan berbasis piksel menggunakan metode NDBI (Normalized Difference Built-up Index) dan MLC (Maximum likelihood Classification).

Metode NDBI digunakan untuk deteksi area terbangun secara otomatis berdasarkan perbedaan nilai NDVI (Normalized Difference Vegetation Index) dan nilai NDBI. Sedangkan, metode MLC didasarkan pada probabilitas suatu piksel dalam kelas tertentu (Qian.dkk, 2007). Asumsi dari algoritma MLC adalah objek yang homogeny selalu menampilkan histogram yang terdistribusi normal (Danoedoro, 2012).

\section{METODE PENELITIAN}

Lokasi yang digunakan dalam penelitian ini adalah Kabupaten Lamongan yang terletak pada $6^{\circ} 51^{\prime}$ - $7^{\circ} 23^{\prime}$ Lintang Selatan dan 112 $33^{\prime}$ - $112^{\circ} 34^{\prime}$ Bujur Timur.

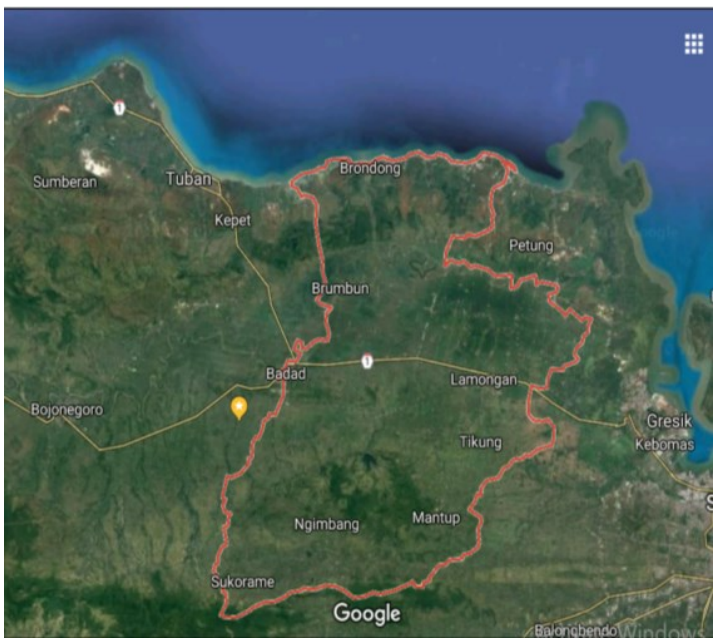

Gambar 1. Lokasi penelitian

Citra satelit yang digunakan dalam penelitian ini adalah citra satelit Landsat 8 tahun 2015 dengan path 118 dan 119 raw 65 . Citra satelit Landsat memiliki resolusi 30 meter. Dilakukan cek geometrik untuk validasi agar mengurangi kesalahan posisi citra satelit. Selain itu, dilakukan konversi digital number ke reflectance menggunakan rumus (USGS, 2019):

$$
\rho_{\lambda}=M_{\rho} Q_{c a l}+A_{\rho}
$$

dimana:

$\mathrm{P} \lambda=T O A$ planetary reflectance without correction for solar angle

$\mathrm{Mp}=$ band-specific multiplicative rescaling factor from the metadata

Qcal = quantized and calibrated standasrd product pxel values (DN)

$\mathrm{A} \rho=$ band-specific additive rescaling factor from the metadata

Dilakukan pemotongan area penelitian sesuai batas administrasi agar pegolahan data sesuai dengan area penelitian yang dilakukan.

Metode klasifikasi Maximum Likelihood merupakan klasifikasi piksel berdasarkan probabilitas kemiripan nilai piksel dari training area yang dilakukan. Sedangkan metode klasifikasi berdasarkan algoritma NDBI merupakan klasifikasi nilai piksel berdasarkan nilai indeks rata-rata.

Zhang et al. (2003) dalam Danoedoro (2012) menggunakan analogi Normalized Difference Vegetation Index (NDVI) untuk mengembangkan indeks area terbangun yang disebut Normalized Difference Built-up Index (NDBI). NDBI digunakan untuk mengkalkulasi area terbangun. Kedua formulasi tersebut adalah:

$N D V I=\frac{B V_{\text {inframerahdekat }}-B V_{\text {merah }}}{B V_{\text {inframerahdekat }}+B V_{\text {merah }}}$

$N D B I=\frac{B V_{\text {inframerahtengah }}-B V_{\text {inframerahdekat }}}{B V_{\text {inframerahtengah }}+B V_{\text {inframerahdekat }}}$

built up area $=N D B I-N D V I$

dimana:

Bv inframerahdekat $=$ saluran inframerah dekat pada kanal citra satelit Landsat 8

$\mathrm{Bv}$ merah $=$ saluran merah pada kanal citra satelit Landsat 8

$\mathrm{Bv}$ inframerah tengah= saluran inframerah tengah pada kanal citra satelit Landsat 8

Klasifikasi menggunakan algoritma NDBI terdiri dari 3 (tiga) tahap yang dilakukan. Tahap pertama yaitu pengolahan citra satelit Landsat 8 menggunakan persamaan 2. Tahap pertama bertujuan 
untuk mendapatkan nilai indeks vegetasi. Tahap kedua yaitu pengolahan citra satelit Landsat 8 menggunakan persamaan 3, tahap ini bertujuan untuk memperoleh nilai indeks bangunan. Tahap yang ketiga yaitu melakukan perhitungan dari tahap yang pertama dan tahap kedua.

\section{HASIL DAN PEMBAHASAN}

\section{Hasil klasifikasi berdasarkan metode MLC}

Pengolahan data klasifikasi metode MLC diperlukan training area sampling untuk menghitung nilai probabilitas kemiripan klasifikasi DN piksel.

Dalam penelitian ini digunakan 3 (tiga) kelas penutup lahan, yaitu vegetasi, perairan, dan area terbangun. Penentuan training area sampling disebarkan secara acak pada area penelitian. Pada Gambar 2. warna merah merupakan training area untuk sampling area terbangun, warna biru untuk area perairan, dan warna hijau untuk area sampling objek vegetasi.

Gambar 3 merupakan hasil klasifikasi area menggunakan metode MLC. Piksel yang berwarna hijau merupakan area yang diklasifikasikan sebagai vegetasi. Piksel yang berwarna merah merupakan area terbangun. Piksel yang berwarna hitam dan terletak didalam area penelitian merupakan perairan.

\section{Hasil klasifikasi berdasarkan algoritma NDBI}

Terdapat 3 (tiga) hasil dari tahap klasifikasi berdasarkan algoritma NDBI. Gambar 4. merupakan hasil perhitungan berdasarkan persamaan 2, yaitu klasifikasi indeksi vegetasi. Klasifikasi NDVI menghasilkan nilai DN dengan rentang -1 sampai +1. Rentang -1 sampai 0 merepresentasikan bahwa area tersebut bukan vegetasi, sedangkan rentang 0 sampai +1 merepresentasikan bahwa area tersebut masuk dalam kategori vegetasi.

Gambar 4. Menunjukkan bahwa piksel yang berwarna hijau dan terdapat dalam batas administrasi merupakan area vegetasi, sedangkan piksel yang berwarna putih merupakan area bukan vegetasi.

Ketentuan nilai rentang untuk klasifikasi menggunakan algoritma NDBI sama seperti rentang pada NDVI yaitu rentang nilai -1 sampai 0 menunjukkan area terbangun, sedangkan rentang nilai 0 sampai +1 menunjukkan area bukan terbangun.

Gambar 5. menunjukkan bahwa warna kuning merupakan piksel yang memiliki indeks bukan area terbangun dan warna merah yang terdapat dalam batas administrasi merupakan piksel yang memiliki indeks area terbangun. Selanjutnya dilakukan perhitungan NDVI dan NDBI yang terdapat dalam Gambar 6.

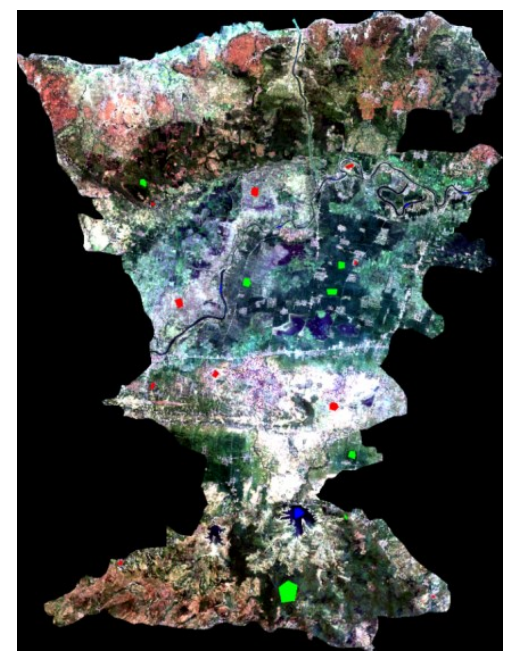

Gambar 2. Persebaran training area sampling

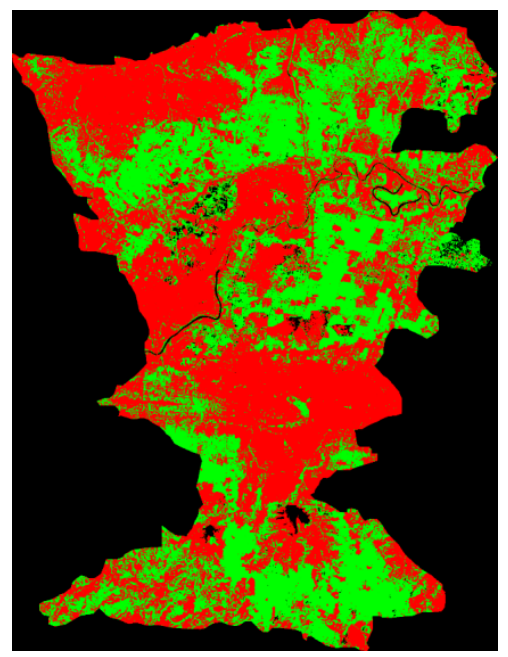

Gambar 3. Hasil klasifikasi metode MLC

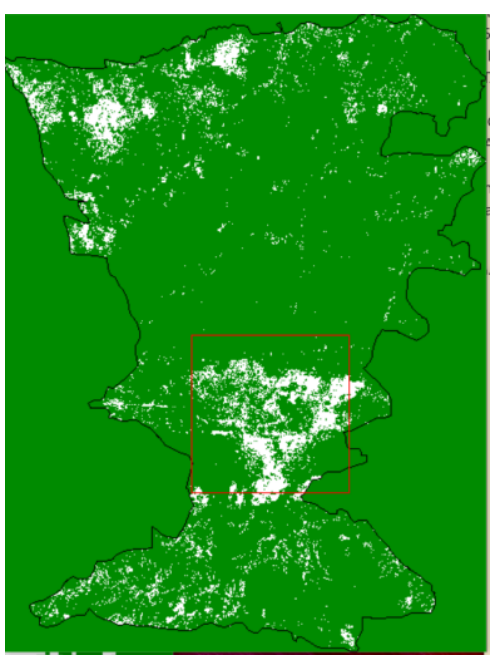

Gambar 4. Hasil klasifikasi menggunakan algoritma NDVI 


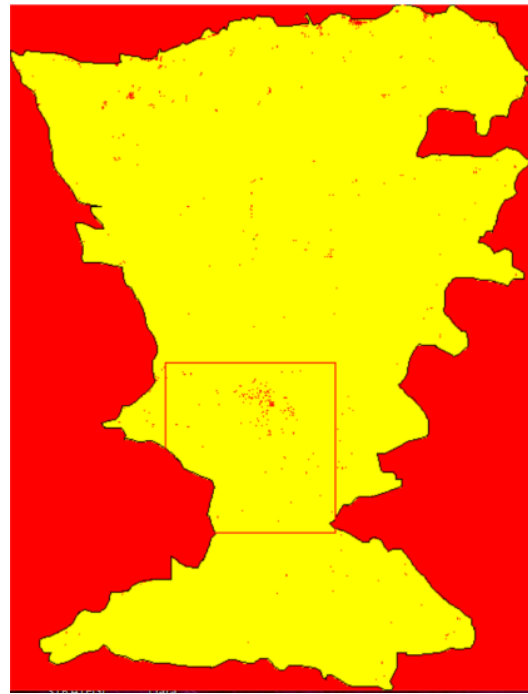

Gambar 5. Hasil klasifikasi menggunakan algoritma NDBI

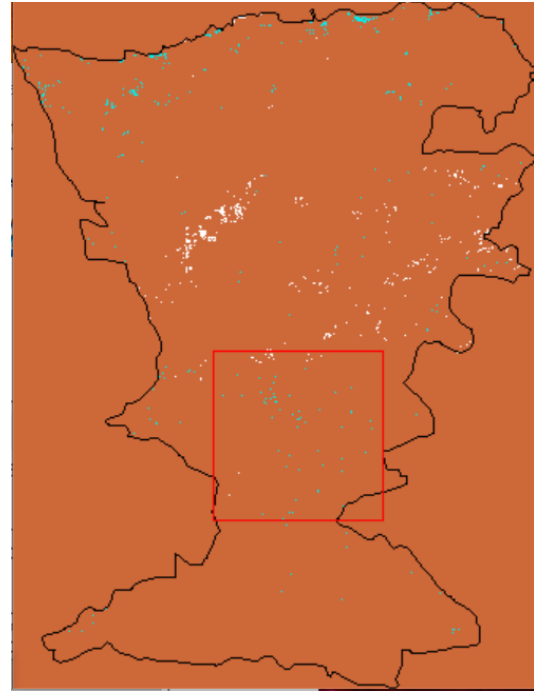

Gambar 6. Hasil klasifikasi area terbangun

pada metode algoritma NDBI terdapat piksel yang tidak terklasifikasi.

Hasil klasifikasi bukan area terbangun menunjukkan bahwa sample pola waduk (berwarna biru tua hingga hitam) pada kombinasi natural color terdeteksi sebagai area terbangun pada klasifikasi berdasarkan algoritma NDBI, sedangkan pada hasil klasifikasi metode MLC sebagian besar pola tersebut terdeteksi sebagai area perairan (warna hitam).

\section{KESIMPULAN} terdapat dalam Tabel 1 digunakan kombinasi natural color sebagai perbandingan terhadap keadaan di lapangan. Secara visual, kelas klasifikasi area terbangun (warna merah) pada metode MLC menghasilkan piksel yang didominasi mendekati sesuai terhadap keadaan yang sebenarnya dibandingkan metode algoritma NDBI (warna coklat).

Klasifikasi kombinasi area terbangun dan bukan terbangun menunjukkan bahwa sungai (berwarna hitam) pada kombinasi natural color terdeteksi bangunan (warna coklat) pada hasil klasifikasi berdasarkan algoritma NDBI. Selain itu, area sawah berdasarkaan keadaan sebenarnya dilapangan, terdeteksi sebagaian area bangunan (warna merah) dan vegetasi (warna hijau) pada metode MLC, sedangkan
Hasil klasifikasi area terbangun menggunakan metode MLC lebih mendekati pada keadaan sebenarnya di lapangan dibandingkan metode algoritma NDBI berdasarkan sample acak lapangan yang digunakan.

Untuk penelitian selanjutnya dapat digunakan training area sampling yang lebih banyak dan kelas klasifikasi yang beragam pada metode MLC.

\section{UCAPAN TERIMA KASIH}

Penelitian ini didanai oleh Lembaga Penelitian dan Pengabdian Masyarakat (LPPM) ITN Malang dalam skema hibah internal. 
Tabel 1. Perbandingan klasifikasi area terbangun berdasarkan metode MLC dan algoritma NDBI

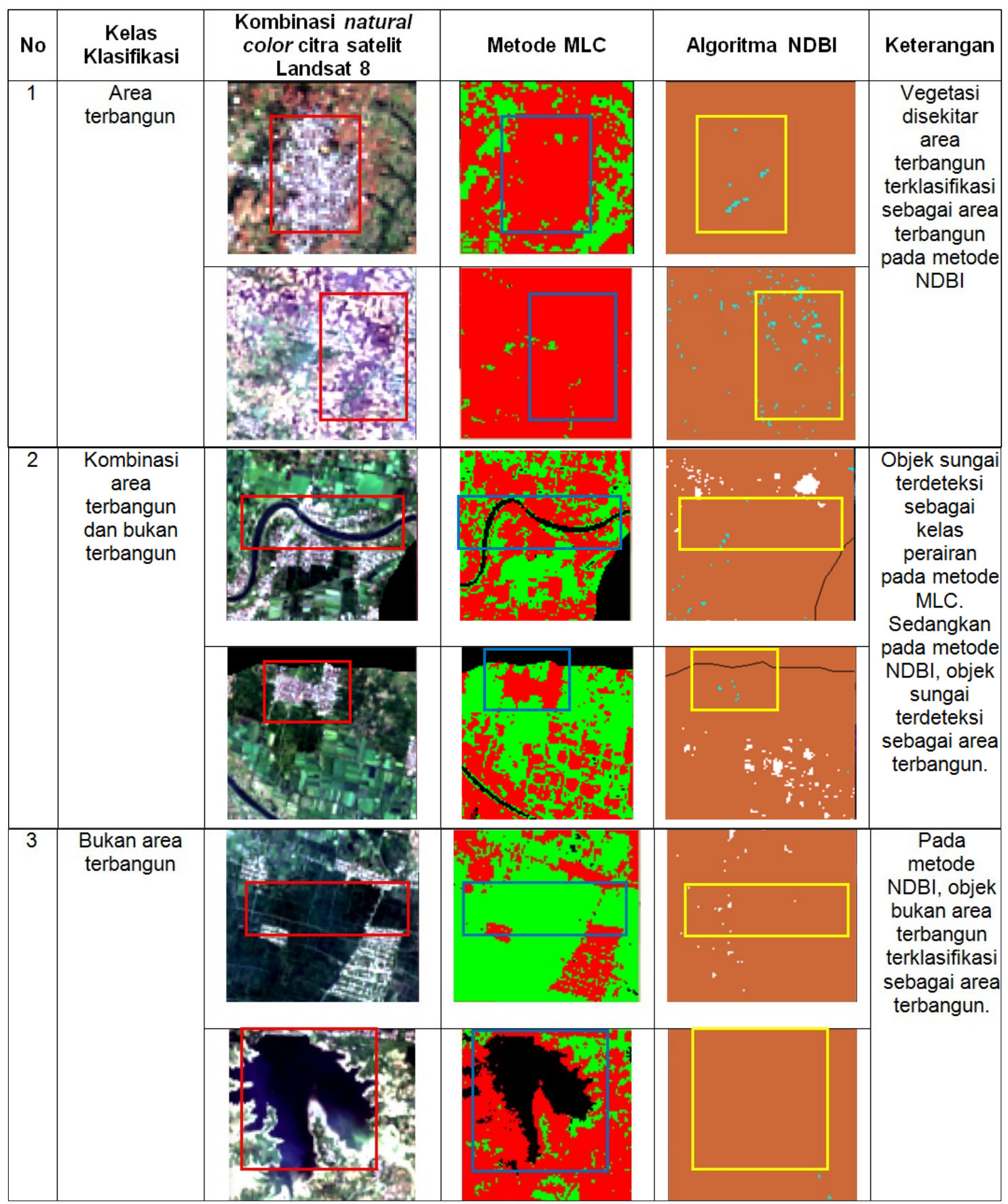




\section{DAFTAR PUSTAKA}

Danoedoro, P. (2012), Pengantar Penginderaan Jauh Digital, Cetakan Pertama, Penerbit Andi, Yogyakarta.

Kamila, A. dan Pai, S.C. (2015), "Urban Growth Monitoring and Analysis of Environmental Impacts on Bankura-I and II Block using Landsat Data", Cloud Publication, Volume 4.

Khamala, E. dan Ottichilo, W. 2002. "Map Updating Using High Resolution Satellite Imagery a Case of the Kingdom of Swaziland". The International Archive of the Photogrammetry, Remote Sensing and Spatial Information Sciences, Vol.XXXIV, Part 6/W6: 89-92.
Qian, J., Zhou, Q., dan Hou, Q. 2007 "Comparison of pixel-based and object-oriented classification methods for extracting built-up areas in Aridzone". ISPRS Workshop on Updating Geo-spatial Databaes with Imagery \& The $5^{\text {th }}$ ISPRS Workshop on DMGISs, Vol.XXXVI, Part 4/W54: 163-171.

USGS. (2019). Landsat. <URL: http://www.landsat.usgs.gov>, diakses pada tanggal 15 April 2019 pukul 14.00 WIB.

Zha, Y., Gao, J., dan Ni, S. 2003. "Use of normalized difference built-up index in automatically mapping urban areas from TM imagery". Taylor n Francis. Volume 24. 